\title{
COMMISSION 46: ASTRONOMY EDUCATION AND DEVELOPMENT ${ }^{1}$
}

(EDUCATION ET DEVELOPPEMENT EN ASTRONOMIE)

\author{
PRESIDENT: Syuzo Isobe \\ VICE-PRESIDENT: Jay Pasachoff \\ ORGANIZING COMMITTEE: Julieta Fierro (Past-President), Alan Batten, \\ Don Wentzel, Michèle Gerbaldi, Richard West, Charles Tolbert, Barrie Jones, \\ John Percy, Derek McNally \& Johannes Andersen (EC representative)
}

\section{Overview}

The most important topic for Commission 46 is that Commission 38 (Exchange of Astronomers) and 46 (Teaching of Astronomy) merged into a single new Commission 46 with the name of Astronomy Education and Development at the XXIV General Assembly held in Manchester, UK, August 16, 2000. The new Commission remains a Commission of the Executive Committee and continues, co-ordinates, and expands the educational and development activities of both present Commissions. To these will be added the 'pre-project' or 'scouting ' mission of the Working Group on World Wide Development of Astronomy of the Executive Committee. The entire budget of the IAU for educational and development activities, including the support sometimes received from ICSU and/or UNESCO is available the new Commission, based upon regularly updated long-term plans and program reviews. Close contact will be maintained with the Executive Committee and the General Secretary to permit quick funding decisions to be made when need be. The Commission 46 Organizing Committee is responsible for planning, co-ordination, and reporting for the overall effort, while specific programs are run in a flexible manner by small, dedicated Program Groups.

Commission 46 is now composed of 9 Program Groups, namely, Advanced Development (AD) chaired by Alan Batten, Teaching for Astronomy Development (TAD) by Don Wentzel, Collaborative Programs (CP) by Syuzo Isobe, International Schools for Young Astronomers (ISYA) by Michèle Gerbaldi, Exchange of Astronomers by Richard West, National Liaison by Jay Pasachoff, Newsletter by Barrie Jones, Solar Eclipse by Jay Pasachoff, and Exchanges of Books, Journals etc. by John Percy. A report of each Program Group is given below.

The terms of reference, rules, and guidelines of Commission 46 are shown in http://physics.open.ac.uk/IAU46.

The next important topic is that the IAU-COSPAR-UN Special Workshop on Education in Astronomy and Basic Space Science was held in conjunction with UNISPACE III, July 20, 21 and 23, 1999 at the Vienna International Center; Austria. This 2.5 day workshop was designed to show how astronomy and basic space science education should become an integral part of how countries build up the scientific capacity to conduct projects in space, and to outline the guidelines that might be developed by the IAU and COSPAR in order to support these activities.

Reviews of actual situations presented how basic science fares in countries with no scientific tradition (Mazlan Othman, Malaysia). They argued for the need to recognize the limited science capabilities in any one such country and to adjust international cooperation to take account of the limitation. Moreover, space activities should be viewed not only as

${ }^{1}$ Commission of the Executive Committee. 
solution for environmental problems, but also as a way to enhance the general scientific understanding and an opportunity to identify and train the most talented people needed to solve a country's problems (Bambang Hidayat, Indonesia) Other papers demonstrated the progress possible when a country had a national leader supporting science (Marcos Machado, Argentina), and identified some of the strategies that countries have used to initiate and develop the basic physical sciences (Don Wentzel, USA).

The summary of existing activities included those of the IAU (mostly but not solely Commission 46 - Teaching of Astronomy), of COSPAR, and of various regional astronomy and space physics associations (e.g. the Working Group on Space Sciences in Africa). Given the context of the meeting, special emphasis was given to the recently initiated Regional Educational Centers for Space Science and Technology, affiliated to the UN, and the Workshop was privileged to provide the first opportunity for the Directors of the four Centers (India, Brazil, Morocco, and Nigeria) to meet together. Productive discussions were held not only among the Directors of these centers, but also with the representatives of the IAU, COSPAR and the UN and led to the decision to form an informal Contact Group for future coordination and possible joint initiatives between all parties.

A day was spent on the main ideas that should be contained in, e.g. future workshops aimed at creating guidelines and producing materials for countries wishing to improve their basic science via astronomy and space science. Julieta Fierro (Mexico) outlined the goals and opportunities to reach the public, Michèle Gerbaldi (France) discussed astronomy in the French schools with emphasis on teacher training, and Isabel Hawkins (USA) and John Percy (Canada) outlined the benefits, challenges, and limitations in bringing actual space science data to the high schools.

Most papers were printed in the journal: Bulletin "Teaching of Astronomy in the Asian-Pacific Region" No. 15 and 16, Editor S. Isobe (e-mail: isobesz@cc.nao.ac.jp).

The workshop closed with a set of concise recommendations which were forwarded to the UNISPACE III meeting:

1. Countries should support education in astronomy and basic science as a key element in a strategy to promote science education in general;

2. Constructive collaboration between the UN Regional Educational Centres in Space Science and Technology and the IAU and COSPAR should be encouraged and supported;

3. People trained in basic space science need jobs in order to usefully serve their home countries (!); and

4. The IAU and COSPAR should start collecting, in a systematic way, their experience both with long-term strategic planning in a number of different environments, and with various types of educational material that exist to teach astronomy at various levels.

The recommendations were discussed, modified and submitted to the main UNISPACE III Conference, and all essential elements of them were included in the Final Report and "Vienna Declaration" of the Conference. With the endorsement of the Report by the UN General Assembly in late 1999, they become part of the recommendations of the United Nations for the next 2-3 decades.

During UNISPACE III many recommendations from different "Technical Forum" were forwarded to the Conference and to a very large extent included in the Final Report of UNISPACE III, and associated recommendations to the UN General Assembly, which became part of the recommendation of the United Nations for the next 2-3 decades.

The full Final Report of UNISPACE III, including the summary "Vienna Declaration on Space and Human Development" as well as the documents of Background and Recommendation of the Conference including the recommendations of all the meetings held as 
part of the "Teaching Forum" are available from the web site of UN Office of Outer Space Affairs at http://www.un.or.at/OOSA/.

Following the recommendation of the UNISPACE III, different Action Teams were set up. One of them is Action Team 17 "Capacity building" brought from our recommendations. Its initiative at the United Nation was taken at its meeting of the Scientific and Technical Subcommittee of the UN Committee of the Peaceful Uses of Outer Space (UN-COPUOS), Vienna, 25 February - 8 March. Action Team 17 consists of several Member States let by Japan, as well as several NGOs, including the IAU and COSPAR. The leading country (Japan) of Action Team 17 tried to extend their activities and held the meeting at UNCOPUOS in June 2002, and has a plan to hold further discussion meeting during the World Space Congress held in Houston, October 2002. It is expected to have some conclusions within one or two years.

\section{Program Group Report for Advance Development (AD)}

PG members: Alan Batten (Chair), A.W. Alsabti, Alexis Troche Boggino, Richard Gray, John Hearnshaw, Mary Kay Hemenway, Yoshihide Kozai, Hakim Malasan, Peter Martinez, Derek McNally, Don Wentzel

During the past triennium there have been three major activities of the Group:

1. Preparation of the proceedings of the Special Session "Astronomy for Developing Countries" held during the Manchester General Assembly. This proceeded on schedule, and the volume of proceedings appeared within a year of the meeting.

2. Preliminary investigation of the possibility of a TAD program in The Philippines. On behalf of the Group, Ed Guinan visited the Philippines and reported on the situation there. Further details on the status of this proposal will be found in another section of the report.

3. On the initiative of A. Alsabti a proposal was made for a half-day session in Sydney on "Advanced Astronomy for Developing Countries". Unfortunately, this did not win approval from the IAU Executive Committee.

During June-July of 2000, Batten attended conferences in Turkey and Korea, learning at first hand about the status of astronomy in these countries. Both countries are economically and astronomically more developed than many he has visited specifically on behalf of the Group and the astronomical community in Korea, in particular, is well-known internationally in several fields of astronomy. The Turkish astronomical community is also thriving, although still quite small and perhaps not yet as well-known internationally as it deserves to be.

\section{Program Group Report for Teaching for Astronomy Development (TAD)}

PG members: Don Wentzel (Chair), Armando Arellano Ferro, Khalil Chamcham, David Clarke, Nguyen Dinh Huan, Derek McNally, John Percy, Maria Cristina Pineda de Carias, Nguyen Quang Rieu, James C. White II

\section{VIETNAM:}

A new bilingual text "Astrophysics" (authors Donat G. Wentzel, Nguyen Quang Rieu, Pham Viet Trinh, Nguyen Dinh Noan, and Nguyen Dinh Huan) was published in December 2000 by Educational Publishing House of Vietnam, with partial financial support by TAD. It is aimed at the astronomy course taught at ten pedagogical universities. In 1999, TAD supported the last of the preparatory conferences, with Nguyen Quang Rieu and Jay White as foreign faculty. The university teachers now using the text received teaching support at conferences in March 2001 and (TAD-supported) in December 2001. 
TAD supported the first issue (December 2000) of the new quarterly Vietnamese journal "Popular Astronomy", published by the Astronomical Society of Vietnam.

In order to make the 45-cm telescope at Hanoi Pedagogical University into a more useful educational tool, TAD supported the travel of Mr. Nguyen Anh Vinh to the UN/ESA workshop in Toulouse (with an opportunity to receive some training under auspices of the Société Populaire Astronomique de Toulouse) and his travel for four months of observational training to Gunma Astronomical Observatory, Japan, and TAD helped pay for the rebuilding of the telescope pedestal.

The Pedagogical University in Ho Chi Minh City has received a 20-cm telescope and CCD through the support of Prof. Y. Kozai and Gunma Observatory. TAD has supported the travel of Mrs. Tran Quoc Ha and her astronomy teaching assistant Mr. Cao Anh Tuan to Gunma Observatory for observational training so as to make the telescope an effective teaching tool.

The only Vietnamese planetarium, in Vinh City, obtained two shows (one donated) from Davis Planetarium (Baltimore, USA), translated and culturally adapted both shows with help from Vinh University astronomers, and started showing them in January 2001 to Vinh City public and schools.

To better plan TAD activities in Vietnam, TAD supported the travel of Prof. Nguyen Dinh Huan (vicepresident, Astronomical Society of Vietnam, rector, Vinh University) to the IAU General Assembly in 2000.

\section{CENTRAL AMERICA:}

TAD supported the travel costs for national delegates and one foreign faculty member to the sixth and seventh Central American Course on Astronomy and Astrophysics, held in 2001 at the University of Costa Rica, San Jose, and in 2002 at the National University of Honduras, Tegucigalpa (and also provided some meeting expenses).

In Nicaragua, astronomy is developing as a teaching subject within the School of Physics at the National University of Nicaragua, Managua. TAD supported Dr. Nidia Morrell (Argentina) to visit and advise, and thereupon provided a CCD and set of filters for the new 20-cm telescope.

In Costa Rica, the School of Physics of the University of Costa Rica, San Jose, is developing an observatory at altitude 3442 meters. TAD is supporting development of a students' solar observing program, at first by sending Ms. Lela Taliashvili to Meudon, France, both to up-date her experience and to progress toward her solar-oriented doctorate.

Jay White (assistant chairperson for TAD) briefly visited Prof. Jorge Paez (Costa Rica), president of the Central American Astronomical Assembly (the organization adhering to the IAU), in order to discuss the most useful support by TAD for future astronomy development in Central America.

In 2001, TAD provided three student travel grants: For Maria Quiroz, student in the Central American M.Sc. program, to travel from Honduras for M.Sc. thesis research with Dr. Silvia Fernandez, Cordoba, Argentina. Local living costs were provided by the National University of Cordoba under an agreement with the Central American Suyapa Observatory, Honduras. The M.Sc. degree has been awarded. For Eduardo Rubio to travel from Guatemala for B.Sc. thesis research with Dr. Armando Arellano, Mexico. Additional support was provided by a fellowship from the Guatemalan CONCYT and SENACYT and an assistantship from the National University of Mexico. The B.Sc. has been awarded. For Alfredo Gomez, student in the Central American M.Sc. program, to travel from Nicaragua for M.Sc. thesis research with Dr. Nidia Morrell, La Plata, Argentina.

\section{MOROCCO:}

The program is centered in the Faculty of Sciences of University Hassan II in Casablanca. The major initial initiative, which led to a significant change in the attitude of the faculty 
toward astronomy, was the acquisition of the IAU traveling telescope and the CCD. The students learned with Dr. David Clarke (Glasgow) how to use the CCD and could then operate the telescope without any assistance.

Travel has been supported for students going to Munich (subject: CCDs and electronics), to Lecce, Italy (subject: a one-year master course Space Systems on Earth Observation), and to Obs. Pic du Midi (for ten days to study there with Dr. Michèle Gerbaldi, France, and take data and data-reduction software back to Casablanca).

TAD aided the computational capability of Prof. Chamcham's academic program, by supporting in part an interdisciplinary collaboration with the University of Pisa, by supporting participation in an Italian-sponsored interdisciplinary workshop in Casablanca on data and image analysis, by providing travel expenses for Mr. Stuart Keir (U.K.) to visit and advise on computing, and by a contribution to a laptop computer needed for the IAU-provided telescope and the educational capabilities of the astronomy program

TAD supported the travel of John Danziger from Trieste to Casablanca for a short course, discussions with students, and advice on developing astronomy, and the travel of Michèle Gerbaldi from Paris to Casablanca for professional planning of astronomy teaching at several schools in Casablanca (expecting to be using a privately donated small telescope). TAD supported six students to attend the Second International School of Plasma Physics held in Casablanca in 2002.

A second university is about to join the TAD program in Morocco. It is Alakhawayn University in the town of Ifrane, with astronomy interests in its Engineering and other programs. Several TAD-supported visiting lecturers are expected to visit both Casablanca and Ifrane.

\section{GENERAL:}

Books, journals, and teaching aids have been provided to several TAD-supported institutions.

\section{PHILIPPINES:}

A new TAD program is expected to support astronomical training of the staff of the Astronomy Research and Development Section (which includes public outreach) of PAGASA, the Philippine national weather agency, including a program to use the new $45-\mathrm{cm}$ telescope (with CCD etc.) donated by the Government of Japan.

\section{Program Group Report for International Schools for Young Astronomers (ISYA)}

\section{PG members: Michèle Gerbaldi (Chair), Edward Guinan}

Since the last General Assembly, two ISYA have been organized successfully.

\section{5th ISYA - Thailand - 2001}

The 25th ISYA took place in Thailand at the University of ChiangMai (January $3-22$, 2001).

All the lectures and practical activities were at the Department of Physics (Faculty of Sciences) and the observations took place at the Sirindhorn Observatory.

The Local Organizing Committee was co-chaired by Prof. B. Soonthornthum (ChiangMai University), and by Prof. Kam Ching Leung (University of Nebraska-Lincoln, USA). Prof. Kam Ching Leung has a long standing collaboration with Prof. B. Soonthornthum, and participated actively to the working out of the planing of the ISYA.

According to the budget, 20 foreign participants (3 women, $17 \mathrm{men}$ ) were invited, from 10 different countries (China (mainland), Hongkong, Taiwan, India, Indonesia, Laos, 
Nepal, Philippines, Vietnam and DPR Korea) and 22 from Thailand (but 3 of them could not come) (3 women, 16 men). Three foreign students cancelled their participation at the very last moment, one from Laos as well as the 2 participants from DPR Korea.

The background of the 36 participants, ranged from finishing their B.Sc. (14 participants), their MSc (9), on the edge of starting their PhD (7), Engineers (3) to 3 participants having already their $\mathrm{PhD}$.

English was the language of the ISYA.

The Thai faculty members were: Sumit Niparaks (Observations, astronomy labs), Nuanwan Sanguansak (Stellar Dynamics), Aniwat Sooksawat (Astronomy web pages), Boonrucksar Soonthornthum (Photometer, stellar photometry, eclipsing binaries analyses)

The foreign faculty members were: Helmut Abt (Spectrographs, spectral classification, radial velocity, stellar rotation, binaries), Kwing $L$. Chan (Solar type atmospheres, solar seismology, convective heat transfer), Kwong-Sang Cheng (High-energy astrophysics, theoretical study of neutron stars and strange stars), Jean-Pierre De Greve (Stellar interior structure, evolutionary models of single stars, evolutionary models of binary stars), Michèle Gerbaldi (stellar fundamental parameters, stellar atmospheres), Ajit Kembhavi (Galaxy classification, morphology shapes, large scale structure, galaxy formation and evolution), Donald W. Kurtz (Variable, peculiar, and Ap stars; high-speed stellar photometry, radial and non-radial pulsation; theoretical modeling), KamChing Leung (Determination of physical parameters of binary stars; irradiation and mass circulation in binary atmospheres)

Several participants gave short talks on their research. Formal and informal sessions of practical activities were organized including exercises on stellar photometry data reduction and image processing.

Observations at the Sirindhorn observatory took place, using mainly the $40 \mathrm{~cm}$, Cassegrain telescope equipped with a small spectrograph and a CCD. A photometer can also be used: SSP-3A, UBVRI filters and solid state detector. Stellar spectra were obtained during 4 observing sessions.

\section{6th ISYA - Argentina - 2002}

On behalf of the Facultad de Ciencias Astronómicas y Geofísicas de la Universidad Nacional de La Plata, Argentina, the organization of the 26th International School for Young Astronomers took place at the Complejo Astronómico El Leoncito (CASLEO), San Juan (altitude $2500 \mathrm{~m}$ ) the major Argentinian National Observatory, under the direction of Prof. Nidia Morrell.

This ISYA could be organized due to special grants by IAU and UNESCO-Paris to overcome the economical crisis in Argentina starting a short time before the ISYA. For the first time, the participants to an ISYA could do observations using a $2.15 \mathrm{~m}$ telescope thanks to the allocation of time by the Scientific Committee of CASLEO: during 11 nights, observational time was available for photometry or spectroscopy.

Dr. Hugo Levato, director of CASLEO, made possible the organization of the ISYA at this observatory.

The number of participants was 28: 14 foreign (2 female, 12 male) from: Brazil, Cuba, Ecuador, Honduras, Nicaragua, Peru, Uruguay, Venezuela. And 14 Argentinian ( 8 female, 6 male). The background of these 28 participants, ranged from finishing their Licenciado degree (nearly equivalent to a MSci. degree) to having started their $\mathrm{PhD}$ about one year ago.

Spanish/English was the language of the ISYA.

The faculty members were: Maria Victoria Alonso (OAC, Córdoba, Argentina - Observatoire Midi-Pyrénées, Toulouse, France) Introduction to Galaxies, Itziar Aretxaga (INAOE, 
Tonantzintla, Mexico) Active Galactic Nuclei, Rodolfo Barbá (FCAG, La Plata, Argentina) Astronomy with Large Astronomical Databases, Guillermo Bosch (FCAG, La Plata, Argentina) Star Forming Regions, Pablo Cincotta (FCAG, La Plata, Argentina) Topics in Theoretical Galactic Dynamics, Sylvio Ferraz Mello (IAG, Sao Paulo, Brazil) Dynamics of Extrasolar Planetary Systems, Diego García Lambas (OAC, Córdoba, Argentina) Cosmology, Michèle Gerbaldi (IAP, Paris, France) Stellar Astrophysics, Ed Guinan (Villanova University, USA) Binaries, The Sun, Mariano Méndez (SRON, The Netherlands) High Energy Astrophysics, Nidia Morrell (FCAG, La Plata, Argentina) Observation and data reduction

A network of computers under LINUX was set up for the practical activities. Specialized software packages were installed for the reduction and analysis of optical (IRAF) and X-ray (XSPEC) observations.

An observing program has been set up in order to make comprehensive observations which may constitute later a short publication. BVRI photometry and intermediate resolution spectroscopy in a selected area were done. Data reductions using dedicated software and analysis of the photometric and spectroscopic observations were done during the practical activities.

\section{Program Group Report for Exchange of Astronomers}

\section{PG members: Richard West (Chair), Charles Tolbert (Vice-Chair)}

\begin{tabular}{lll}
\hline Name & Origin & Destination \\
\hline A. Arellano & Mexico City (Mexico) & Bangalore (India) \\
P. Rosenzweig & Merida (Venezuela) & Bloomington (Indiana, USA) \\
J. Sperauskas & Vilnius (Lithuania) & Tucson (Arizona, USA) \\
A. Kazlauskas & Vilnius (Lithuania) & Tucson (Arizona, USA) \\
V.A. Brumberg & St. Petersburg (Russia) & Paris (France) \\
B. Efremova & Sofia (Bulgaria) & Mexico City (Mexico) \\
J. Stil & Toronto (Canada) & Pune (India) \\
J.F.V. Marquez & Havana (Cuba) & Mexico City (Mexico) \\
A. Pai & Pune (India) & Potsdam (Germany) \\
I. Park & Seoul (Korea) & Lexington (Kentucky, USA) \\
A.N. Petrov & Moscow (Russia) & Pune, India \\
A.N. Ramaprakash & Pune (India) & Pasadena (California, USA) \\
C. Sanchez & Madrid (Spain) & Calgary (Canada) \\
N.I. Shatsky & Moscow (Russia) & Brussels (Belgium) \\
M. Skulsky & Lviv (Ukrainia) & La Plata (Argentina) \\
K. Tian & Shanghai (PR China) & Victoria, B.C: (Canada) \\
C. Tout & Budapest (Hungary) & Melbourne (Australia) \\
J. Urama & Nsukka (Nigeria) & Hartebeesthoek (South Africa) \\
A.M. Vasquez & Buenos Aires (Argentina) & Cambridge (Mass, USA) \\
K. Yuce & Ankara (Turkey) & Bamberg (Germany) \\
Ch. Li & Shanghai (PR China) & Victoria (Canada) \\
R. Brar & Kingston (Canada) & Pune (India) \\
C. Valotto & Cordoba (Argentina) & Ithaca (USA) \\
N. Padilla & Cordoba (Argentina) & Durham (UK) \\
B.A. Korany & Helwan (Egypt) & Potsdam (Germany) \\
A.A. Ubachukwu & Nsukka (Nigeria) & Pune (India) \\
I. Park & Sejong (Korea) & Louisiana (USA) \\
J. Javaraiah & Bangalore (India) & Paris (France) \\
R. Vasundhara & Bangalore (India) & Paris (France) \\
\hline
\end{tabular}


28 grants were made available during the triennium October 1, 1999 - September 30, 2002, as listed above.

Some of these were distributed by IAU Commission 38 (Exchange of Astronomers, which was discontinued in August 2000, at the time of the IAU General Assembly in Manchester). The activities were continued under the auspices of Commission 46 by the present Program Group after that date.

A certain decline of the number of applications was noted, especially after mid-2001.

It is noted that several recent cases are concerned with stays shorter than the stipulated three months. Moreover, some applications were received in connection with intended observing stays and were thus incompatible with the current rules. In view of these trends, and also on the background of greatly improved communication facilities between geographically distant institutions, it may be useful to re-discuss the rules for this IAU program in order to ensure its continued efficiency.

\section{Program Group Report for Newsletter}

\section{PG members: Barrie Jones (Chair), Andy Norton, Tracey Moore}

Barrie Jones collects and selects material for the Newsletter, and edits it into a Word document that is reproduced for hard copy circulation. From Word he exports an html version that is then placed on the C46 website by Tracey Moore. Tracey Moore informs people via an email list that the latest Newsletter is available. She keeps this list updated.

Tracey Moore is responsible for day-to-day updating of all aspects of the C46 website, a role she has filled for some time, but that has only recently been recognized by including her in the program group membership.

Andy Norton is responsible for website development, and thus he has a strategic role. The URL of the website is http://physics.open.ac.uk/IAU46

\section{THE NEWSLETTERS}

In the period under review (2000-2002) there have been two editions of the Newsletter per year, in March and in October. The October 2002 issue is currently being prepared.

Issues vary in length from about 5000 to 11000 words, plus illustrations. Regular items are an editorial, a message from the President, features (including news from program groups), news of meetings, and a list of the officers and organizing committee of Commission 46. In the issues preceding the triennial General Assembly there are triennial reports from National Liaisons.

Hard copy of the Newsletter is sent to 161 postal addresses, including 8 that are either National Liaisons or certain members of the Organizing Committee. 162 people are informed by email that a new edition is on the web, again including 8 that are either National Liaisons or certain members of the Organizing Committee.

\section{COSTS}

The only costs charged to the IAU (in Paris) are reprographic costs for making the hard copies, and the postage costs for distributing them. Per edition, these charges on the IAU range from about $£ 150$ to $£ 200$.

\section{Program Group Report for Solar Eclipses}

\section{PG members: Jay M. Pasachoff (Chair), Ralph Chou, Julieta Fierro}

The Program Group provides information and advice about safe observation of partial, annular, and total solar eclipses and can try to help publicize astronomy in general when a country's attention is focused on astronomy by the approach of an eclipse. It maintains a 
Web page for the general public at www.eclipses.info. This Web page is similar to that of the Working Group on Eclipses but has safety and other information of particular interest to the general public appearing first, before maps and more technical information.

The total solar eclipse of 21 June 2001 swept across southern Africa, and provided partial phases for all of Africa south of the Sahara. The Working Group on Eclipses of Division II of the IAU maintained a homepage at www.totalsolareclipse.net (which links to www.williams.edu/astronomy/IAU_eclipses) that provided links to maps, information about observing eclipses, and information on eye safety at eclipses, including filter evaluations by Ralph Chou. Jay Pasachoff lectured about watching eclipses safely at a ProfessionalAmateur Conference on Solar Eclipses held at Antwerp in November 2000 and at various venues in Zambia in March and June 2001.

In spite of the best efforts of all professionals and educators concerned, confusion reigned about when to look at the eclipse through filters and when directly. The growing popularity of solar viewers of Mylar in eyeglass form has probably contributed to the confusion. We are working with the makers of such glasses and viewers to label the products more clearly, assuming people do not read accompanying instructions. In spite of numerous newspaper interviews, newspapers continued to print incorrect information how to observe eclipses.

Solar filter material was distributed at low cost or no cost to universities in Zambia and Zimbabwe, and representatives of many countries in the zone of partial eclipse were advised on safe observing methods. No eye injuries have been reported, to our knowledge. National liaisons were appointed in Zambia, Zimbabwe, and South Africa, and they did their best to provide accurate information.

The annular eclipse of 14 December 2001 in Costa Rica provided partial phases from northwestern South America through Central America to all of the United States except for the east. The 10 June 2002 annular eclipse provided partial phases for viewers in eastern Asia (including Japan, China, Russia, and Korea) and northwestern Australia and then ranged across the Pacific Ocean to western Mexico, United States, and Canada. Annularity was viewed in certain Pacific Islands and near Puerto Vallarta, Mexico, usually through clouds. Images can be seen in links from www.eclipses.info.

The 4 December 2002 total eclipse provided partial phases across all of Africa except its northern rim and, at sunset, western Australia. Information about safe watching of partial phases of eclipses was widely disseminated in those regions, though, as usual, the local ophthalmological society sent out some misleading and overly harsh warnings.

Maps for future eclipses are available on the Web site, www.eclipses.info.

\section{Program Group Report for Exchanges of Books and Journals}

\section{PG members: John Percy (Chair), Darrell Hoff}

A small number of organizations, including the IAU, the American Astronomical Society, the Astronomical Society of the Pacific, the Royal Astronomical Society of Canada, the American Association of Variable Star Observers, Sky Publishing Corporation, Saunders College Publishing, and probably some organizations that we do not know about, send copies of publications to selected addresses in the astronomically-developing countries. The challenges are to select publications which would be useful and appropriate, to locate a person in the astronomically-developing country who would put the publication to the best use, and to pay for the large cost of shipping books or journals.

\section{Future Meetings}

Commission 46 is the primary sponsor of a Special Session at the 2003 IAU General Assembly. The topic is Effective Teaching and Learning of Astronomy, primarily at the school level. The emphasis is on education techniques which have been proven to be effective through research and/or experience. 


\section{Individual Activities}

Commission 46 is mainly composed of National Liaison of each member country who works under the Program Group of National Liaison chaired by Jay Pasachoff. Each National Liaison is requested to write the triennial report appearing in the Commission 46 Newsletter (see http://physics.open.ac.uk/IAU46).

Some members organized international education meetings. Here are brief informations of those meeting which we get.

- The $9^{\text {th }}$ European and $5^{\text {th }}$ Euro-Asia Astronomical Society Conference took place in Moscow 29 May - 3 June 2000. The title of this joint meeting was "European Astronomy at the turn of the millennium".

- The $4^{\text {th }}$ EAAE international summer school organized by the European Association for Astronomy Education took place in Tavira Portugal 3-8 July 2000. The theme of that summer school was "Astronomy navigation". It is open to primary, secondary, and tertiary education teachers interested in the teaching of Astronomy.

- The RAS/IAU meeting at the end of the IAU General Assembly at Manchester UK in 18 August 2000 was organized by the UK Royal Astronomical Society and IAU Commission 46. It is called "Astronomy research projects for school and university students". This discussion meeting explored ways in which students at school and university can participate their understanding of astronomy and develop useful skills.

- International Conference on primary school science and mathematics organized by the International Council for Science (ICSU) and its Committee on Capacity Building in Science (CCBS) was held in Beijing 1-4 November 2000. This is the first meeting on education by ICSU. Over 60 scientists, educators, teachers and governmental representatives and the private sectors from over 20 nations gathered to discuss problems and opportunities in science and mathematics education in primary schools.

- The $6^{\text {th }}$ international conference of teaching of astronomy organized by the UNIFF of the Technical University of Catalonia took place in Villanova (near Barcelona) Spain 23-25 November 2000. It is open to primary, secondary, and tertiary education teachers wanting to present teaching activities developed by other teachers.

- Tenth UN/ESA Workshop on basic space science was held in Mauritius 25-29 June 2001. It is oriented to the opportunities for developing countries to participate in world space observations and in the utilization of space technologies.

- The United Nations has declared 4-10 October of each year as World Space Week (WSP). This is a celebration at the international level of the contribution that space science and technology can make to the betterment of the human condition.

- COSPAR-IAU Workshop was held at the UN Regional Center in Brazil. The IAU Commission 46 Program Groups - Collaboration Programs and the International School for Young Astronomers had been preparing the long-planned COSPAR-IAU cosponsored workshop and this is the first 'cooperation program' since the Workshop at UNISPACE III.

- Communicating astronomy meeting organized by the Instituto de Astrofisica de Canarias was held at La Laguna in Tenerife, Canary Islands, Spain 25 February - 1 March 2002.

- There is a journal of "Bulletin of Teaching of Astronomy in the Asian-Pacific Region" edited by Syuzo Isobe, starting in 1989 and reaching to the volume 18. A web-based journal, the "Astronomy Education Review" has been launched under the aegis of the US National Optical Astronomy Observatories and the Astronomical Society of the Pacific (http://aer.noao.edu). 
The Program Group on Collaborative Programs, whose members are Syuzo Isobe (Chair), Johannes Andersen, Christopher Corbally, David Crawford, Julieta Fierro, Hans Haubold, Seigbert Raither, Dale Smith, James C. White II, P. Willekens, Peter Willmore, has been working with UN, ICSU, COSPAR, with several successful outputs as shown above. Such collaborations are expected to expand much wider level.

This report was written with much help of Commission 46 members and especially its organizing cornmittee members.

Syuzo Isobe

President of the Commission 